\title{
For the Safety and Benefit of Current and Future Patients
}

\author{
Mats G. Hansson \\ Centre for Bioethics, Department of Public Health and Caring Sciences, Uppsala Science Park, Uppsala, Sweden
}

\section{Key Words}

Biobanks $\cdot$ Ethics $\cdot$ Safety $\cdot$ Integrity $\cdot$ Informed consent

\begin{abstract}
Pathology biobanks are vital assets for medical care and treatment of current and future patients. In association with good clinical data they are also useful for biomedical research regarding the underlying mechanisms of human disease. Recent regulations have suggested the obtainment of a specific and explicit informed consent as a prerequisite for using human tissue samples with these ends in mind. However, the choice and strict use of informed consent for balancing conflicting interests associated with biobank-related research can in practice be detrimental to patient safety with regard to diagnosis, medical care and treatment. In this article I argue that a 'safety principle' should have priority and suggest how this could be implemented in clinical practice and in association with biomedical research.
\end{abstract}

Copyright $\odot 2007$ S. Karger AG, Basel

This publication reflects only the author's views. The European Community is not liable for any use that may be made of the information herein.

\section{KARGER}

Fax +4161306 1234

E-Mail karger@karger.ch

www.karger.com
(C) 2007 S. Karger AG, Basel

1015-2008/07/0744-0198\$23.50/0

Accessible online at:

www.karger.com/pat

\section{Introduction}

Well-managed pathology biobanks combined with clinical data of good quality constitute important health resources for current as well as future patients [1-4]. Recently these pathology biobanks have been the object of ethical debate and in some instances special legislation, e.g. in Iceland and Sweden. Legislations as well as ethical guidelines are the result of a balancing of the different interests that are believed to be at stake in association with collection, storage and use of biobank samples. In Sweden, legislation was called for by a rush order leading to a situation where vital patient interests could not be fulfilled by doctors, pathologists and researchers. However, after the Swedish Biobank Act (2002: 297) came into effect in January 2003, guidelines and practical solutions have been implemented in order to balance conflicting interests and promote good biobank practice. In this article I will draw attention to the basic purpose of sampling, indicate some lessons learned from the Swedish experience, discuss the question whether renewed consent is advisable, suggest an alternative approach to regulation, and, finally suggest a practical manual for biobankrelated research. 


\section{Biobanks as Resources for Health}

The main reason for storing human tissue samples is the donor's own medical care and treatment. The largest biobanks contain samples which are stored in clinical pathology and cytology, and after microbiological serum analyses. It is a question of samples which are taken routinely in order to determine the correct medical diagnosis. It can, for example, concern a patient who has a tumor in the breast. The patient has earlier been treated for cancer of the kidney. By analyzing the new sample and comparing it with the earlier stored sample, one can determine if it is a question of a secondary tumor, or of a new tumor of another type. The ability to compare old with new samples is often necessary in order to make the right diagnosis and provide the right treatment. For children who are born with severe immune deficiency syndrome, a bone marrow transplant is sometimes the only solution. The Swedish so-called Tobias Register contains bone marrow samples which have been donated by children. Samples from this biobank can be a sick child's only chance of having a functioning immune defense system.

New parents are asked regularly if the midwife can take a sample from the heel or from the back of the hand of the child. With the help of this sample, which is stored in the so-called PKU register, one can see whether the child is suffering from the metabolic disorder phenylketonuria. If this is not treated, the child is likely to suffer from developmental and neurological disorders, symptoms which normally cannot be detected in the newborn child. With the help of a special diet, the child can develop normally. Several other maladies can be identified with the help of these samples.

Within health and hospital care, stored samples are used for quality development, education and research. Through research, one can study and take preventive measures against illnesses. The biobanks are also important instruments for clinical testing of new medicines. All these goals for storing samples within health and hospital care are directly or indirectly motivated by safety requirements in the diagnosis, care and treatment of current and future patients, directly in the case of the diagnosis and treatment of patients, and indirectly by virtue of the fact that medical education, research and quality developments are all ultimately pursued with the health of current and future patients in mind. Taken as a whole, biobanks constitute an important health resource in all countries.

\section{Renewed Consent Is Not Advisable}

Samples which are taken routinely and stored within the health and hospital care sector, are, then, necessary to guarantee, as far as possible, the patient's best interests with respect to diagnosis, care and treatment. By donating a sample, the patient participates in creating better conditions for his or her own care and treatment. There must be few people who would object to this. Nor would the majority wish to specify the purposes too narrowly. We do not know when we are going to be afflicted by a certain illness, and the existence of large, well-defined and high-quality biobanks to which many have contributed, can be of use to us when we least imagine. On the other hand, it is conceivable that individuals who have given samples for medical purposes would have objections, for example, to insurance companies or the police using these samples for quite different purposes.

It is neither reasonable nor desirable to specify too precisely the medical purposes of storing human biological material [5]. A model where one simply says that it is for 'the patient's own care and treatment and related matters' or in the case of special research projects one gives the purpose simply as 'biomedical research', would probably be more in keeping with people's interest. This is borne out by two recently conducted surveys, one carried out for donors to an existing biobank in Sweden, and the other which was based on a representative sample of the Swedish population [6-8]. Overall, the results point among other things to a willingness to accept broad goals and a high degree of trust in genetic research which is conducted with the aim of acquiring better knowledge of the development and treatment of illnesses. There was also strong support for the work of the research ethics committees. Obtaining informed consent is in itself uncontroversial when a medical research study begins. When it is the case of research studies which make use of material collected earlier, there is, however, reason to be restrictive about allowing information and consent arrangements which entail that one must go back to the sample donor and request permission to use the sample for a new medical purpose. The samples in a biobank, which have been collected for a specific purpose, can sometimes be useful in testing new scientific hypotheses about the underlying mechanisms of human diseases. For the researcher, it can be difficult to predict scientific development, and it is therefore impossible to give precise information about possible goals when the first sample is taken. If one applies the consent norm strictly, and chooses to ask the donor about the new research aim, the donor 
can, on the one hand, feel both respected and a participant in the decision-making process. However, if one is aware of the costs for such an information-and-consent arrangement, the result can just as well be - perhaps are more likely to be - the opposite. To ask for renewed consent would undermine the donor's possibilities of participating in the development of scientific knowledge. The donor is more likely to experience a lack of respect in being asked yet again.

The reason for this is that if one chooses to ask again, one will never achieve, for various practical reasons, a $100 \%$ reply response, even in cases where people were interested in participating. At most, one can reckon on a reply frequency in the range $70-80 \%$ and in many cases much lower. Nor has one much control over the response deficit. It can turn out that it is the most interesting people, from the viewpoint of the study, who have not replied. The cost of asking again is therefore a significantly poorer scientific basis for the results one hopes to achieve. These results can be of crucial importance for the possibility of developing medical diagnoses, care and treatment. Respect for the integrity of the sample donor ought to include the possibility of handing over scrutiny to a research ethics committee, which is democratically constituted and is able to see how the work is pursued and how decisions are made [5, 8-10]. The individual's interest in not being exposed to an invasion of his personal matters is still satisfied, since personal information which can be linked both to the biological material and to the information which can be obtained from it is secret [11].

\section{Informed Consent Is Not a General Solution - Lessons from Sweden}

From the perspective of current and future patients there may be several interests that need to be balanced in association with collection of tissue samples and their use for quality control and research. In the normal case, it is the patient who decides to donate or accept that a biopsy is taken and he or she can have privacy concerns associated with the storage and handling both of the biological samples and of personal data. It is important also to recognize that patients are the end users of the results of biomedical research, e.g. new opportunities for diagnosis, new medical products and improved treatment.

Inspired by the Convention on Biomedicine and $\mathrm{Hu}-$ man Rights from the European Council, the chief balancing principle in the Swedish biobank law is the requirement of an explicit and specified informed consent [12].
If no such consent is documented, a sample may not be stored for a period longer than 2 months. The choice of informed consent as the leading guiding principle may be seen as an indication of respect for the integrity of the donors of tissue samples $[10,13]$. However, it has also had the effect that vital interests of those individuals incapable of providing such a consent - for example, incompetent adults are less protected since the law does not allow samples from them to be stored. In the short-term perspective this law seriously endangered patient safety with regard to diagnosis, treatment and prevention. In the long-term perspective the law implies that these patient groups are discriminated since biobank-related research using their own tissue samples was no longer possible on their behalf.

However, the National Board of Health and Welfare issued recommendations and guidelines in December 2002 that came out in print on January 7, 2003, where they suggested an order of priority when different interests come into conflict, as they so obviously did for these patient groups (SOSFS 2002:11, 4 chapter, $4 \$$ ). They judged that patient safety with regard to diagnosis, treatment, care and prevention should have priority when balanced against the integrity of these individuals. This meant that storage of samples from these patients without consent is legal. Later on a new law for regulating research on human subjects was proposed. The Ethical Review Act (2003: 460) came into effect January 1, 2004. This law stated that an ethical review board (ERB) had the sovereign right and duty to select an appropriate information and consent procedure for a research study, including the possibility to approve of research without any obtainment of informed consent $(15,20,21 \S \S)$. This law implied that biobank research done without consent for the benefit of these vulnerable patient groups was no longer unlawful.

In practice, then, a Swedish authority has suggested that informed consent is not sufficient as a guiding principle. It should in some circumstances be replaced with a concern for patient safety with regard to diagnosis, treatment, care and prevention. The Swedish parliament has, furthermore, given the ERB the privilege and the duty to select between different information and consent procedures. These two principles, the 'safety first' principle and the 'sovereignty of the ERB', represent a kind of rollback policy regarding the alleged moral status of informed consent that could be implemented and thus be of benefit not only to incompetent adults.

The policy is consistent with the view of the European Council Convention on Biomedicine and Human Rights 
which in one of its commentaries states that information and consent arrangements may vary according to the circumstances, thus allowing for flexibility since the express consent of an individual to the use of parts of his body is not systematically needed' (Ref. 12, Commentary 137 to Article 22). The need of putting the requirement of an explicit and specified informed consent into perspective is as described above also supported by several public surveys. Furthermore, a survey in the Västerbotten region of Sweden revealed that potential donors of tissue material were more concerned with safety in the handling of personal information than with the kind of research that is carried out with the help of the samples [14]. In a representative sample of the Swedish population a majority was in favor of biobank research and wanted an information and consent policy where the right to an informed consent could be waived and handed over to the ERB [8].

\section{Informed Consent in Practice}

The requirement of the Swedish biobank law to obtain an explicit and specified informed consent for each sample incurred great problems for the hospitals. During a patient consultation, information should be given not only regarding the disease or the immediate questions related to diagnosis. One should also inform about the biobank law and other potential uses of the sample, e.g. for quality improvement, medical education and biomedical research. Time should be assigned not only for information but also for the patient to understand the information and provide a documentation of the consent. For the hospitals and county councils this was not practically feasible and the increased cost for each consultation was not acceptable. I was member of a working group at the Swedish Federation of County Councils that developed practical and uniform information and consent procedures for collection of blood and tissue materials in association with hospital care and visits at hospitals in Sweden.

This is how we reasoned. Taking into consideration:

(1) that the safety of the patient with regard to diagnosis, treatment, care and prevention has priority and, accordingly, it is important that samples are stored and used,

(2) the fact that most patients are willing to donate samples and are in favour of medical purposes and other compatible purposes, e.g. quality improvement, medical education and biomedical research,

For the Safety and Benefit of Current and Future Patients
(3) that public trust is partly based on the fact that county councils and hospitals use taxes in a cost-efficient way,

(4) that patient autonomy and the views of a minority that may be sceptical to storage for all or some purposes may be respected by using an instrument of withdrawal, and

(5) that all research studies based on the biobank must be approved by an ERB who has the duty and the privilege to decide if the consent obtained at the hospital is sufficient or if a renewed, more specific consent is needed.

The following order was suggested and is currently being implemented:

(1) General information about the biobank law and purposes for collection of samples are available in the waiting rooms through posters and leaflets. The information includes examples of biobank-related research and its use for improving diagnosis and treatment.

(2) The consulting clinician gives brief information about the purposes of sampling and the possibility to withdraw consent later on. A recommendation is given that the sample should be stored.

(3) If the patient approves, the clinician submits the referral without further notice. A text on the referral form indicates that submitting a referral implies a yes to all lawful purposes (i.e. care and treatment of the patient, medical education, quality improvement and research).

(4) If the patient does not approve of storage or does not approve to one or several purposes for sampling, the clinician puts a cross in a box on the referral form sent to the laboratory and the patient is given a 'no-talon' to take home together with more detailed information about the purposes of sampling. The talon is to be submitted to the director or the supervisor of the biobank.

(5) After receiving a 'no-talon' the laboratory either destroys the sample or codes it for appropriate use in accordance with the wish of the patient.

(6) A sample with a referral where the 'no-box' is ticked can be used for diagnosis but not for other purposes until the 'no-talon' has arrived.

Except from point six, this procedure is practically feasible, it shows respect for the majority view while acknowledging the interests of the minority and it shows respect for autonomy by letting a patient who wants to take information home for further reflection. Each sample is traceable. The 'no-box' on the referral creates practical problems because in some cases the 'no-talon' never arrives from the patient and the reason for this is not

Pathobiology 2007;74:198-205 201 
known to the director or supervisor of the biobank. It might be patients who after reflection changed their mind from a 'no' to a 'yes' but forgot to report this. In order to evade this uncertainty a time limit could be introduced, for example stating that if the 'no-talon' has not arrived after 1 month the 'no' will automatically be changed to a 'yes'.

\section{Biobanks as Medical Registries - An Alternative Approach for Regulation}

Individuals, as far as their own personal matters are concerned, have an interest in being left in peace but they also wish to participate in the possibilities which are available to citizens in a society. This includes the possibility of being able to have access to new medical knowledge. The donor has interests both at the beginning of a process intended to expand knowledge, when a sample is taken and stored, and at the conclusion, when the new knowledge is put to use in diagnosis, preventive measures, or treatment. Participation, however, means more than just personally enjoying the fruits of this knowledge. Without the cooperation of many these goals cannot be achieved. For that reason, one ought in this context to note that the scientific value of biobanks increase, the more complete they are, and the more relevant information they contain or can be linked to.

The Swedish Biobanks Act gives individuals the right to withdraw their consent, and to have a sample destroyed or made unidentifiable. Such a stipulation follows logically from a strict interpretation of the consent norm as a principle for balancing interests. However, it fails to take sufficient account of the desires of individuals to participate with others in a system where a common good can be achieved.

An alternative regulative framework for biobanks would have been to apply the same procedure as is the case when using medical registers for quality improvement and for research. Because of their public interest importance, many of these registers in Sweden have been established on a legislative basis by the Swedish Parliament and the National Board of Health and Welfare, and they do not admit any right on the part of individuals to have their information removed. One example of such a register is the National Cancer Register. Individual integrity in the sense of protection of personal sensitive information is assured by rigorous confidentiality requirements. Individual integrity in terms of respect for a person's moral and political authority is satisfied by a democratic and transparent process for the establishment and administration of these registers.

One might object to this argument and maintain that the very possibility of withdrawing one's consent and having the sample destroyed or depersonalized implies a respect for the donor as a citizen with moral authority. It is also conceivable that some individuals have strong personal reasons for not wishing to participate in a certain type of medical research. These interests should be respected as far as possible, but legislators and the authorities concerned must also apply a balancing principle which weighs one interest against others and where ultimately it is those that are worst off in society who should be favored in the outcome. In this particular case, the interests current and future patients have in access to new medical treatment must also be taken into account. This interest can be one of which a person who is ill or someone with a relative, who died from cancer, can be acutely aware. If, therefore, it is the case that allowing people to withdraw their consent has particularly negative effect on those who are already worst off in society, there is reason to abstain from this possibility. The interest of the sick in being cured should be given higher priority than a healthy donor's opportunity to have his attitude to a certain type of medical research respected. Protection of the sample donor's privacy is still respected in the sense that the information is, and remains, strictly confidential.

\section{Manual for Management of Ethical and Legal Aspects of International Biobank Research}

Doctors and researchers sometimes feel frustrated when philosophers and lawyers argue above their heads and influence policymaking in matters where they feel that vital patient and research interests are neglected. Some matters need to be focus for continuous ethical and legal discussion, but one should also be able to give practical advise based on the current ethical and legal frameworks. The following manual should be seen as a first step towards such a manual (based partly on refs. 5, 20). The key element in this manual is the information given to the patient/donor when new material is collected. In data protection legislations and in regulations of biobank research the patient/donor has the sovereign right to decide if and how personal data and tissue material may be used, e.g. a 'yes' to use of personal data must be respected by an $\mathrm{ERB}$ and by the data protection authorities. 


\section{Premises}

(1) Collaboration between researchers, doctors and ERBs is essential in order to increase knowledge about medical diagnosis, treatment and prevention [15].

(2) Biobank research is ordinarily based on an informed consent by the donor of the biological material.

(3) Both the biological material and personal information about the donor(s) should be coded and safely protected.

(4) Each research project involving human biological material should be approved by an ERB or other appropriate authority.

(5) A record should be kept that describes the samples in a biobank and specifies the kind of consent attached to each sample.

(6) This manual is intended as a practical guidance to researchers in international collaborations. It is based on national legislations, European directives, international conventions and academic publications [12, 16-19]. It does not relieve the researcher from seeking guidance in and follow national law and standards of scientific and clinical practice, e.g. Good Laboratory Practice (GLP), Good Clinical Practice (GCP) and Good Management Practice (GMP).

\section{Points to Consider regarding New Collection of Samples}

The points to consider are specified as part of the donor/patient information. This information with specifications is to be submitted to an ERB, or other appropriate authority for approval of the initial sampling and of each subsequent research project using these samples.

Information should specify:

(1) The purpose of the research. This could be broadly described as 'cancer research', 'research on autoimmune diseases' or 'biomedical research' and argument for this in turn presented to the ERB [5].

(2) The nature of the research, i.e. that the research involves genetic analysis and use of both biological material and personal information including specification of the source(s) of this material and information.

(3) Who is responsible for the biobank and the identity of the data controller (the person/representative responsible for the security of personal data).

(4) When relevant, that the research is conducted in international collaboration including both academic research groups and private companies implying that both tissue samples and personal information will/may be transferred for analysis between the partners.

(5) That this collaboration is based on legally binding agreements between the partners which specify that the samples and the information are coded and that they will be either returned, destroyed, archived or anonymized after completion of analysis or project.

(6) That both the biological material and the personal information is safely stored and coded so that the material and the information (i) is protected from destruction, (ii) is not accessible by unauthorized persons, and (iii) makes each sample and individual information traceable.

(7) That the sample is given one code, the information another code and that a third code is needed in order to link data from the analysis of the sample with personal data, specifying that the code keys are safely stored so that they (i) are protected from destruction and (ii) will not be accessible to unauthorized persons.

(8) That results of the research will be accessible only through publication in scientific journals.

(9) That, if successful, the results of the research may also lead to inventions that will be patented.

(10) That the consenting donor may withdraw her/his consent without specifying any reason for this.

\section{Points to Consider regarding Previously Collected Samples}

The points to consider should be specified in the information to an ERB (or other appropriate authority). First, points 1-9 above apply also here. Information should further specify what kinds of consent, if any, that have been obtained when the samples were collected. On the basis that ERBs or other relevant authorities have been given the discretionary scope of determining if an informed consent is needed and if so, what kind of information and consent procedures that are appropriate, the researcher should provide an argument acknowledging the following points [20]:

(1) A sample will not be used if the donor has explicitly objected to its use [Ref. 19, Art. 16].

(2) When no explicit consent was obtained or requested when the samples were collected, and taking into consideration (i) the research interests of donors, (ii) the strict coding procedures proposed, (iii) that secrecy laws apply to any handling of sensitive information, and (iv) that vital research interests are at stake, it is suggested that samples may be used without consent. 
(3) When consent included use for medical research, but was limited to a specific study or specific research and was silent about other research, it is suggested that samples may be used without new consent.

(4) When consent included use for medical research, but was explicitly restricted to specific uses different from the present one, it is suggested that these samples will not be included in the proposed project.

\section{Comments}

(1) Regarding research involving children, incompetent adults or deceased persons the following may be proxies: For children it is their legal guardians (usually one or both parents), for incompetent adults a relevant proxy has to be suggested (legislation differs) and for deceased persons it is usually their relatives.

(2) Regarding nomenclature of coding, etc., it is suggested that the recommendations by EMEA are used [21]. They recommend that regarding anonymous samples there are no links to the individual donor (although there may be general descriptions like 'man, age 50-55, cholesterol level $>240 \mathrm{mg} / \mathrm{dl}$ '). Identified samples are linked to the individual in a way that makes them immediately identifiable. A simple code is a direct link to the individual, usually through a random set of numbers or letters, or a bar code. A double code implies that in order to link the sample and the data to the individual a second code is needed. Anonymized are samples that earlier have been identified or coded but the identification, or the code and the code key have been destroyed, so there is no longer any link to the individual.

\section{Conclusion}

Collection, storage and use of human tissue samples are ordinarily based on an explicit informed consent. When samples are taken on a routine basis in hospital care, patient safety with regard to diagnosis, medical care and treatment should be the main ethical concern. This implies broadly described purposes and, in some cases, collection of samples without such a consent. An ERB should normally not require a renewed consent when these samples, or other previously collected samples, are to be used for biomedical research. Having regard to the right of the donor/patient do decide about the use of personal data as laid down in international regulations and national legislations, information in association with new research projects should be specific and explicit regarding the use of both data and biological samples.

\section{Acknowledgement}

The research for this publication was supported by the EU Sixth Framework Programmes AutoCure and CCPRB.

\section{References}

1 Sigstad E, Lie AK, Luostarinen T, Dillner J, Jellum E, Lehtinen M, Thoresen S, Abeler V: A prospective study of the relationship between prediagnostic human papillomavirus seropositivity and HPV DANN in subsequent cervical carcinomas. Br J Cancer 2002; 87:175-180

2 Kaijser M: Examples from Swedish biobank research; in Hansson MG, Levin M (eds): Biobanks as Resources of Health. Uppsala, Uppsala University, 2003, pp 33-50.

3 Lindberg BS: Clinical data - a necessary requirement for realizing the potential of biobanks; in Hansson MG, Levin M (eds): Biobanks as Resources of Health. Uppsala, Uppsala University, 2003, pp 21-32.

-4 Sundstrom P, Juto P, Wadell G, Hallmans G, Svenningsson A, Nystrom L, Dillner J, Forsgren L: An altered immune response to Epstein-Barr virus in multiple sclerosis: a prospective study. Neurology 2004;62:22772282.
Hansson MG, Dillner J, Bartram CR, Carlsson J, Helgesson G: Should donors be allowed to give broad consent to future biobank research? Lancet Oncol 2006; 7: 266-269.

6 Stegmayr B, Asplund K: Informed consent for genetic research on blood stored for more than a decade: a population-based study. BMJ 2002;325:634-635.

7 Kettis Lindblad Å, Ring L, Viberth E, Hansson MG: Genetic research and donation of tissue samples to biobanks. What do potential sample donors in the Swedish general public think? Eur J Public Health 2006;4: 433-440.

8 Kettis Lindblad Å, Ring L, Viberth E, Hansson MG: Perceptions of potential donors in the Swedish public towards information and consent procedures in relation to use of human tissue samples in biobanks: populationbased study. Scand J Public Health 2006;1-9: PrEview article.
Hansson MG: Building on relationships of trust in biobank research. J Med Ethics 2005; 31:415-418.

10 Hansson MG: Combining efficiency and concerns about integrity when using human biobanks. Stud Hist Philos Biol Biomed Sci 2006;37:520-532.

11 Von Essen U: Biobanksforskning - forskares möjligheter att få tillgång till vävnadsmaterial och personuppgifter. Förvaltningsrättslig Tidskrift 2003;2:197-214.

12 Council of Europe: Convention for the protection of human rights and dignity of the human being with regard to the application of biology and medicine. Convention on $\mathrm{Hu}-$ man Rights and Biomedicine. Oviedo 1997, ETS No 164.

13 Hansson MG: Balancing the quality of consent. J Med Ethics 1998;24:182-187. 
14 Hoeyer K, Olofsson B-O, Mjörndal T, Lynöe $\mathrm{N}$ : Informed consent and biobanks: a population-based study of attitudes towards tissue donation for genetic research. Scand J Public Health 2004;32:224-229.

15 Guidelines for the Implementation of the Universal Declaration on the Human Genome and Human Rights, Accepted 16.11. 1999 by UNESCO; 30C/Resolution 23.

16 Directive 95/46/EC of the European Parliament and the Council of 24 October 1995 on the protection of individuals with regard to the processing of personal data and on the free movement of such data (1995).
17 Directive 2001/20/EC of the European Parliament and of the Council of 4 April 2001 on the approximation of the laws, regulations and administrative provisions of the Member States relating to the implementation of good clinical practice in the conduct of clinical trails on medicinal products for human use (2001).

18 Council of Europe: Explanatory Report to the Convention on Human Rights and Biomedicine. Strasbourg, Directorate of Legal Affairs, 1996.
19 Council of Europe: Draft explanatory report to the proposal for an instrument on the use of archived human biological materials in biomedical research. Strasbourg, Steering Committee on Bioethics, 14 October 2002.

20 Helgesson G, Dillner J, Carlson J, Bartram CR, Hansson MG: Information and consent procedures in international research using previously collected biobank samples. Nat Biotechnol, in press.

21 Position paper on terminology in pharmacogenetics. Committee for Proprietary $\mathrm{Me}$ dicinal Products (CPMP), EMEA/CPMP/ 3070/01. 